\title{
Augmented reality (AR) for visualising solar system motion
}

\author{
S Gumilar $^{1}$, A Ismail ${ }^{2}$, IF Amalia ${ }^{3}$, DD Bhakti ${ }^{4}$, and A Malik ${ }^{5}$ \\ \{surya.gumilarr@gmail.com ${ }^{1}$ \} \\ Program Studi Pendidikan Fisika, Institut Pendidikan Indonesia, Jl. Pahlawan No.32, Garut 44151, \\ Indonesia $^{1}$ \\ Program Studi Sistem Informasi, Institut Pendidikan Indonesia, Jl. Pahlawan No.32, Garut 44151, \\ Indonesia $^{2}$ \\ Program Studi Pendidikan Fisika, UIN Sunan Gunung Djati, Jl. A.H. Nasution No.105, Bandung 44151, \\ Indonesia $^{3}$
}

\begin{abstract}
Teaching solar system motion frequently utilizes picture model or real modelling apparatus to facilitate students' conceptual understanding. However, these cases did not show comprehensively how visualization of solar system motion runs alike the real solar system motion. This present study aims to develop an application of solar system motion using AR as an instructional media of science classroom. Web Aurasma Based Studio and HP Reveal were used to develop this application-these have six stages including concept, design, material collecting, assembly, testing, and distribution. The findings reveal that the application was highly applicable to visualize the motion of solar system. The implication of this present study indeed can be a way to enlarge using of AR in science teaching and learning.
\end{abstract}

Keywords: Augmented reality, solar system motion, learning media.

\section{Introduction}

The development of Information and Communication Technology today is growing rapidly. These developments have brought major changes in various fields of life, including in the world of education. For example, the learning process that takes place in the world of education can involve technological assistance. The insertion of technology aims to increase human understanding of what is learned. In this context, technology helps students to better understand the concepts being studied.

One technology that is used as a learning aid is augmented reality (AR). AR shows the process of combining real and virtual world made through computers. The boundary between the two worlds is very thin [1]. This means that AR facilitates the real environment by adding virtual objects. Based on the hardware used, AR can be made using desktop or mobile [2]. In addition, based on the marker, making AR can be divided into two, namely image based, and location based [3].

Many studies in the field of education focus on the application of AR. Some AR designs are done in the form of games [4], and also in the form of books [5][6]. The results of this study indicate that the application of AR in the learning process contributes positively in changing students' understanding of concepts. For example, the application of AR in the process of learning physics can improve understanding of the concept of electricity [7]. In the 
face of student activities in the laboratory, the application of AR can also increase the interest and motivation of students to do physics practicum [8]. This means that AR facilitates students to understand concepts that are abstract or difficult to visualize.

If you review physics learning, one of the concepts that are difficult to visualize is the concept of motion of the solar system [9]. Students tend to understand this concept using static models from teaching and learning media. Although this model can show models of solar system systems, this model cannot directly observe how the solar system moves. To bridge this, this study aims to develop learning media that are directed to provide visualization of the motion of the solar system. The implication of this research is that the media developed can be used as alternative learning media to provide a deep understanding of the concept of how each planet moves towards the center of the solar system.

\section{Method}

The research method utilized in this study is the development research method [10]. The researcher used this research method because the focus of the researcher was to produce learning multimedia products and to be tested on a limited testing. The multimedia development methodology consists of six stages, namely concept, design, collecting materials, assembly, testing and distribution and evaluation, as shown in figure 1.

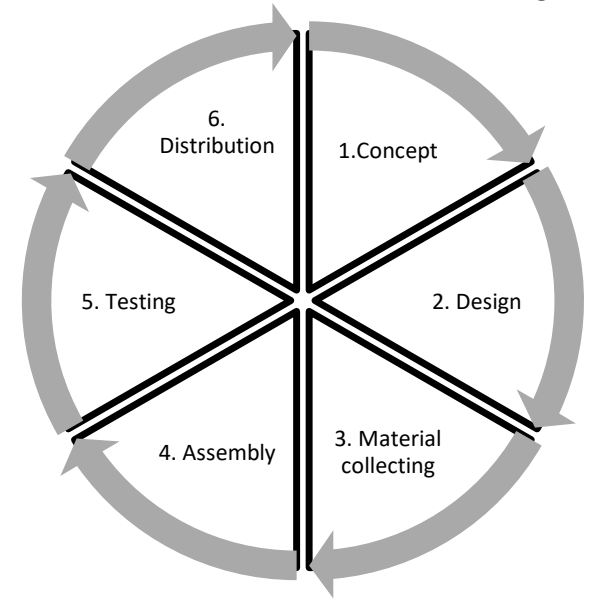

Fig. 1 Developmental research method

\section{Result and Discussion}

\subsection{Concept}

At this time the process of collecting data is done by observation and direct interviews with physics teachers who teach astronomy lessons in science subjects. This is done so that users of the type of application and the purpose of the application can support. The steps taken in this concept are:

- Determine the purpose of using learning media. 
- Analyze based on the use of multimedia-based learning media in the classroom.

- Identify student characteristics through direct classroom observation and interviews with teachers.

- Analyzing students' skills in using technology.

\subsection{Design}

At this stage multimedia augmented reality is designed according to the needs of users, namely teachers and students who conduct learning. The design starts with compiling the program content program, determines the order of presentation and arranging the learning flow in the form of a flowchart. This is intended to make the development of multimediabased learning more focused. The design steps include:

- Writing material texts will be made as multimedia-based learning media. The material is the motion of the solar system.

- Arrange the learning path in the form of a flowchart

- Screen media design

- Arranging the outline of content in the media consists of: marker markers in the form of flashcard-shaped images, the material from the solar system in the form of video, which is made to make it easier for students to search for multimedia at Aurasma.

\subsection{Material Collecting}

At this stage, material collection is needed in the manufacture of AR. The materials needed are as follows:

- Images used as markers in this application are obtained from the Internet free of charge, with modifications in certain parts to meet the requirements. The downloaded images are then processed using the Adobe Illustrator CS5 application

- Audio video was developed using Adobe After Effects. The video development process was then built by combining several components including video and audio. The results are then saved in MP4 format. The format selection is based on the application specifications (Aurasma) as well as adequate quality picture and sound results.

\subsection{Assembly}

This stage is the stage of making all multimedia objects or materials. At this stage AR is made using Aurasma or mobile phone reveal. The steps taken in making AR learning media are as follows:

- Select the image that has been downloaded or made before to make the marker.

- Enter the selected image into the Aurasma studio

- Select the video that was created

- Enter videos or animations that will be made into content in augmented reality

- Give the name augmented reality that is made so that later it will be easier to search for augmented reality at Aurasma.

\subsection{Testing}

After the application development process is complete, the next step is testing. Testing is carried out with the aim of verifying whether the application has been running properly according to the design made previously. The test is done by changing the distance between the image marker and the smartphone that has multimedia AR. The test results can be seen in table 1 . 
Table 1. The Distance of test result

\begin{tabular}{ccl}
\hline No & Distance $(\mathbf{c m})$ & \multicolumn{1}{c}{ Result } \\
\hline 1 & 10 & AR content appeared well \\
2 & 15 & AR content appeared well \\
3 & 20 & AR content appeared well \\
4 & 25 & AR content appeared well \\
5 & 30 & AR content appeared well \\
6 & 35 & Sometimes AR content appeared well \\
7 & 45 & AR content is not appeared \\
\hline
\end{tabular}

The test results show that on the distance $10-30 \mathrm{~cm}$ between the marker and the smartphone used can display satisfying Augmented Reality content. While at a distance of 35$40 \mathrm{~cm}$ augmented reality content sometimes appears, sometimes not, and at a distance of 45 $\mathrm{cm}$ augmented reality content does not appear at all because the smartphone camera that is used cannot capture the marker clearly so that augmented reality content does not appear.

\subsection{Distribution}

Distribution phase is the process in which the Augmented Reality application is then printed on paper in the form of a Flashcard. The reason for using Flashcard is because the flashcard is simpler than books or other learning media so that it will provide convenience in the learning process.

\section{Conclusions}

From the results of the above research, two conclusions were obtained. First, learning media that use Augmented Reality Technology can be used as alternative media in classroom learning, specifically for physics learning in the concept of motion of the solar system. Second, AR learning media using Flashcard will provide convenience in the learning process and video display in augmented reality can provide more motivation and attention for children in science learning, in particular in celestial motion. The implication of this research is to contribute to the development of innovative physics learning.

\section{Acknowledgments}

The author would like to thank the chancellor of the Institut Pendidikan Indonesia "Nizar Alam Hamdani" who has provided financial support to the authors so that we can complete this article. We also would like to thank to all those who helped in collecting research data.

\section{References}

[1] Azuma R T 1997. "A Survey of Augmented Reality", Presence: Teleoperators and Virtual Environments. vol. 6, no. 4, 355-385

[2] Broll W, Lindt I., Herbst I, Ohlenburg J, Braun A K, and Wetzel R 2008 Toward next-gen mobile AR games. IEEE Computer Graphics and Applications, vol 28, no. 4, 40-48.

[3] Cheng KH, and Tsai C C 2013 Affordances of augmented reality in science learning: Suggestions for future research. Journal of science education and technology, vol 22 no 4, 449-462. 
[4] Klopfer E , and Sheldon J 2010 Augmenting your own reality: Student authoring of science-based augmented reality games. New directions for youth development, vol 2010 no128, 85-94.

[5] Dünser A, Walker L, Horner H, and Bentall D 2012 Creating interactive physics education books with augmented reality. In Proceedings of the 24th Australian computer-human interaction conference 107-114

[6] Clark A, and Dünser A 2012 An interactive augmented reality coloring book. IEEE Symposium on 3D User Interfaces (3DUI) 7-10

[7] Martín-Gutiérrez J, Fabiani P, Benesova W, Meneses M D, and Mora CE 2015. Augmented reality to promote collaborative and autonomous learning in higher education. Computers in human behavior, vol 51, 752-761.

[8] Hruntova T V, Yechkalo Y V, Striuk A M , and Pikilnyak A V 2018 October .Augmented Reality Tools in Physics Training at Higher Technical Educational Institutions. In Proceedings of the 1st International Workshop on Augmented Reality in Education Kryvyi Rih, Ukraine No. 2257, 33-40

[9] Plummer J D, Wasko K D, and Slagle C. 2011 Children learning to explain daily celestial motion: Understanding astronomy across moving frames of reference. International Journal of Science Education, vo 33 no14 19631992

[10] Sutopo. 2006. Metodologi Penelitian Kualitatif. Surakarta: UNS. 